\title{
Gonadotropins and steroid hormones in older people: their mutual connections and relations to body mass indices
}

\author{
Marek Pawlikowski' , Tomasz Kostka², Hanna Pisarek², Agnieszka Guligowska², Jacek Świętosławski ${ }^{3}$, \\ Łukasz Kroc'2, Bartłomiej Sołtysik², Katarzyna Winczyk ${ }^{3}$ \\ ${ }^{1}$ Department of Immunoendocrinology, Chair of Endocrinology, Medical University of Lodz, Lodz, Poland \\ ${ }^{2}$ Department of Geriatrics, Chair of Geriatrics, Medical University of Lodz, Lodz, Poland \\ ${ }^{3}$ Department of Neuroendocrinology, Interdepartmental Chair of Laboratory and Molecular Diagnostics, Medical University of Lodz, \\ Lodz, Poland
}

\begin{abstract}
Introduction: Aging in mammals, including man, is accompanied by deep changes in hormone secretion. In the majority of cases, hormone secretion (mostly of gonadal steroids and adrenocortical hormone dehydroepiandrosterone - DHEA) undergoes pronounced decrease. This decrease is thought to contribute to the progression of aging. In contrast, the secretion of gonadotropins is sharply increased in older adults, as a result of gonadal deficiency. Recent data indicate that gonadotropin excess may also, by itself, influence the aging process. The aim of the present study was to investigate the mutual relation between steroid hormones and gonadotropins and their effect on body mass indices in older people.

Material and methods: In a group of 100 patients (61 women and 39 men) aged over 75 years, blood serum concentrations of folliclestimulating hormone (FSH), luteinising hormone (LH), oestradiol (E2), testosterone, dehydroepiandrosterone sulphate (DHEAs), and cortisol were measured. All the patients were measured for the following: body weight $(\mathrm{kg})$, body mass index $(\mathrm{BMI})\left(\mathrm{kg} / \mathrm{m}^{2}\right)$, and waist-to-height ratio (WtHR). The differences of the numerical data were evaluated by Student's t-test and the correlations between them by means of Pearson's test.

Results and conclusions: The most interesting finding of this study was to show that FSH and LH are negatively correlated with body mass and indices such as BMI and WtHR in older women. Because in older women the mediation of ovary is unlikely, we conclude that gonadotropins may influence the body mass by their direct extra-gonadal action. (Endokrynol Pol 2019; 70 (6): 484-488)
\end{abstract}

Key words: human aging; gonadotropins; testosterone; oestradiol; DHEAs; cortisol; body mass indices

\section{Introduction}

Aging in mammals, including man, is accompanied by deep changes in hormone secretion. The principal phenomenon is a decrease of gonadal hormone secretion both in females and males, although in women this process is faster and more sudden than in men. A large decrease of gonadal hormones, as well as the adrenocortical hormone dehydroepiandrosterone (DHEA), were shown to play an important role in the progress of aging process in both sexes (for review see: $1-3$ ). The fall of gonadal hormones leads to an increase of secretion of pituitary gonadotropins - follicle stimulating hormone (FSH) and luteinising hormone ( $\mathrm{LH}$ ) - because of a failure of the negative feedback mechanism. However, in contrast to the decrease of gonadal hormones, the excess of FSH and LH was for a long time considered to be not meaningful. In 1994 one of the authors of the present paper proposed a hypothesis that the gonadotropin excess might also contribute to the aging process [4]. This presumption is based on the earlier findings showing that gonadotropins exert direct extra-gonadal actions, which are sometimes deleterious [5-8]. More recent studies confirm the possibility of direct gonadotropin actions beyond the reproductive system. The presence of $\mathrm{LH} /$ chorionic gonadotropin receptors was revealed in the adrenal cortex [9-11] and the peripheral and central nervous system [12-14]. It was suggested that the high levels of LH that occur in advanced age could be involved in the impairment of the cognitive functions in elderly human subjects and in the pathogenesis of Alzheimer's disease [15-18]. The FSH receptors were identified in osteoclasts and chondrocytes [19], and FSH was shown to stimulate the osteoclast differentiation [20]. The role of FSH in bone loss in older people beyond the oestrogen deficiency was hypothesised [20-22]. The possibilities of the direct extra-gonadal actions of gonadotropins and their roles in aging were recently reviewed [23]. 
The aim of the present study was to investigate the relation between hormone levels (with special reference to gonadotropins) and body mass indices in older patients.

\section{Material and methods}

\section{Patients}

The project was approved by the Bioethical Committee of the Medical University of Lodz, decision number RNN/363/17/KE from $21^{\text {st }}$ November 2017. The study material comprised 100 patients: 61 women (aged at the time of the investigation 76-90 years; mean age 80.61 years) and 39 men (aged 76-88 years; mean age 79.56 years). All of the patients had the following measurements: body weight $(\mathrm{kg})$, body mass index (BMI) $\left(\mathrm{kg} / \mathrm{m}^{2}\right)$, waist-to-height ratio (WtHR).

\section{Methods \\ The quantitative determinations of the following hormone levels in blood serum were performed: follicle-stimulating hormone (FSH), luteinising hormone (LH), oestradiol testosterone, dehydroepi- androsterone sulphate (DHEAs), cortisol. Blood samples were taken from the cubital vein in the morning. For determinations, we used technology based on the competitive or sandwich chemilumines- cence immunoassays (CLIA). The measurements were performed on a LIAISON XL analyser from DiaSorin Inc. (Saluggia, VC, Italy or Stillwater, MN, USA) using the kits produced by this company and dedicated to the abovementioned analyser. The differences of the mean values and correlations of the numerical data were evaluated by Student's t-test and Pearson's test, respectively.}

\section{Results}

The mean serum concentrations of the hormones examined in the present study are presented in Table I. As can be seen there, the mean concentrations of FSH and LH are significantly higher in women in comparison to men $(\mathrm{p}<0.001)$. In both genders the concentrations of FSH were higher than that of LH ( $p<0.001)$. On the other hand, the mean concentrations of DHEAs $(p<0.05)$, testosterone $(p<0.001)$, and E2 $(p<0.001)$ are significantly higher in men as compared to women. FSH and LH are positively correlated between them in both investigated groups (women $\mathrm{r}=+0.6986$, men $\mathrm{r}=+0.7848$ ). In contrast, FSH and LH levels are not correlated significantly with testosterone, E2, DHEAs, and cortisol in women or in men. A negative correlation can be observed with gonadotropins and gonadal steroids when calculated for both genders together (FSH vs. testosterone $r=-0.6728$, LH vs. testosterone $r=-0.5649$, FSH vs. E2 $\mathrm{r}=-0.5968$, LH vs. E2 $\mathrm{r}=-0.4916)$. Testosterone is positively correlated to E2 in both genders (women $r=0.3224$, men $r=0.6926$ ) and to DHEAs in men $(r=+0.7268)$. Some tendency (albeit not significant) occurs also between testosterone and cortisol in both genders (women $r=+0.1736$, men $r=+0.1971$ ). Moreover, E2 correlates positively with DHEAs in women $(\mathrm{r}=+0.3199)$. No significant correlations of cortisol concentrations and other investigated hormones were found. Interesting relations were found between gonadotropin levels and body mass indices of the investigated patients. The significant negative correlations were observed between $\mathrm{FSH}$ or $\mathrm{LH}$ and body mass in the group of women (FSH, $\mathrm{r}=-0.4144$, Fig. 1; LH, $\mathrm{r}=-0.3378$; Fig. 2). In the group of women, the negative correlations can also be noticed between FSH ( $r=-0.34892$, Fig. 3$)$ or LH and BMI ( $r=-0.2689$, Fig. 4). The similar negative correlations exist in this group between FSH or LH and WtHR (FSH, r $=-0.3477$, Fig. 5; LH, $r=-0.2566$, Fig. 6). The correlations of the remaining examined hormones and body mass indices are rather scarce. Only a negative correlation between testosterone and body mass in men $(r=-0.3544)$ and positive correlation with $\mathrm{WtHR}$ in women $(\mathrm{r}=+0.3293)$ were observed. None of the investigated hormones except gonadotropins correlated with BMI.

\section{Discussion and conclusions}

To the best of our knowledge this is the first study investigating the mutual relations between steroid hormones and gonadotropins and their effect on body mass indices in very advanced age. Our findings concerning FSH and LH levels in older women and men (higher values in women and higher elevation of FSH in comparison to LH in both genders) are concordant with the previous studies (for review see: 1,2 ). The

Table I. The mean body mass, body mass index (BMI), waist-to-height ratio (WtHR), and serum concentrations of hormones. Comparison of two group of gender by Student's t-test

\begin{tabular}{lccccccccc}
\hline & $\begin{array}{c}\text { Body mass } \\
{[\mathbf{k g}]}\end{array}$ & $\begin{array}{c}\text { BMI } \\
{\left[\mathbf{k g} / \mathbf{m}^{2}\right]}\end{array}$ & WtHR & $\begin{array}{c}\text { FSH } \\
{[\mathrm{mlU} / \mathrm{mL}]}\end{array}$ & $\begin{array}{c}\text { LH } \\
{[\mathrm{mlU} / \mathbf{m L}]}\end{array}$ & $\begin{array}{c}\text { E2 } \\
{[\mathrm{pmol} / \mathbf{L}]}\end{array}$ & $\begin{array}{c}\text { T } \\
{[\mathrm{nmol} / \mathbf{L}]}\end{array}$ & $\begin{array}{c}\text { DHEAS } \\
{[\mu \mathrm{g} / \mathbf{d L}]}\end{array}$ & $\begin{array}{c}\text { Cortisol } \\
{[\mu \mathrm{g} / \mathrm{dL}]}\end{array}$ \\
\hline \multirow{2}{*}{ Women } & $69.3 \pm$ & $28.5 \pm$ & $0.59 \pm$ & $87.9 \pm$ & $21.2 \pm$ & $56.5 \pm$ & $0.79 \pm$ & $42.5 \pm$ & $14.9 \pm$ \\
& 12.72 & 5.14 & 0.07 & 27.17 & 7.53 & 18.88 & 0.43 & 28.84 & 7.35 \\
\hline \multirow{2}{*}{ Men } & $79.0 \pm$ & $28.1 \pm$ & $0.59 \pm$ & $23.3 \pm$ & $8.3 \pm$ & $113.6 \pm$ & $12.1 \pm$ & $58.2 \pm$ & $17.3 \pm$ \\
& 10.13 & 3.15 & 0.06 & 24.40 & 7.01 & 36.79 & 5.41 & 36.27 & 5.76 \\
\hline $\mathrm{p}$ & $<0.001$ & $>0.05$ & $>0.05$ & $<0.001$ & $<0.001$ & $<0.001$ & $<0.001$ & $<0.05$ & $>0.05$ \\
\hline
\end{tabular}

FSH — follicle-stimulating hormone; LH — luteinising hormone; E2 — oestradiol testosterone; DHEAS — dehydroepiandrosterone sulphate 


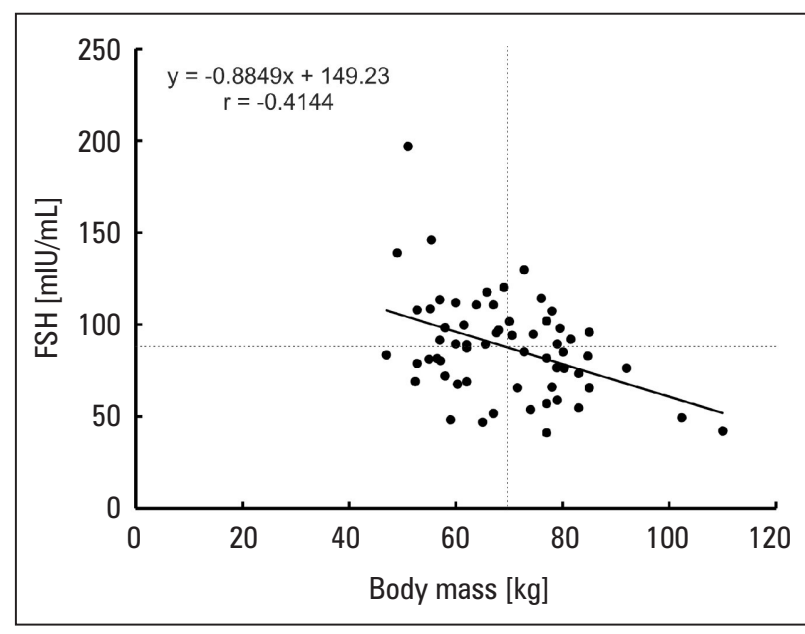

Figure 1. Scatter plot of correlation between body mass and follicle-stimulating hormone (FSH) for women

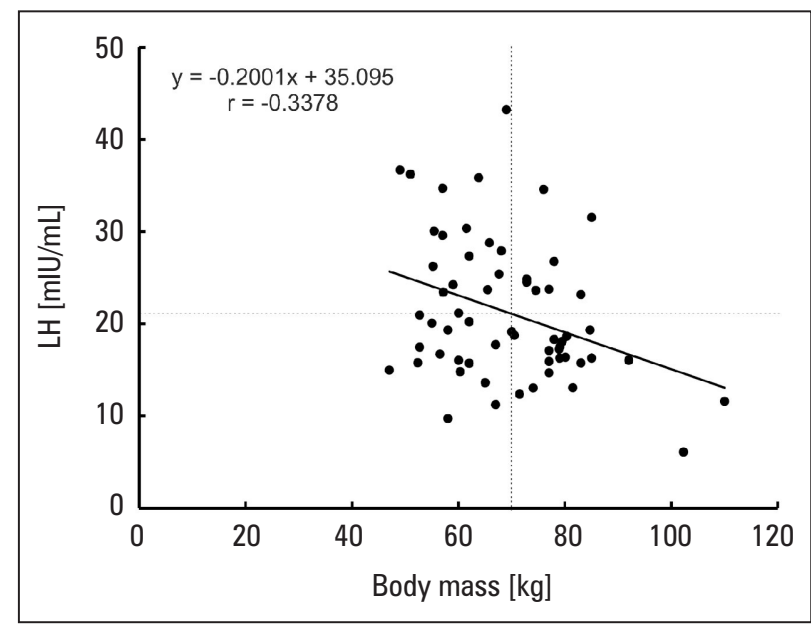

Figure 2. Scatter plot of correlation between body mass and luteinising hormone (LH) for women

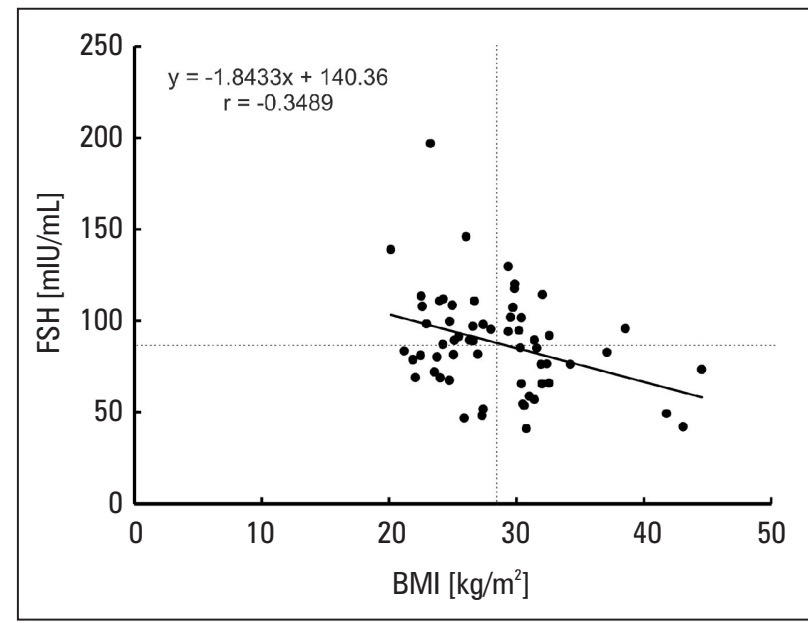

Figure 3. Scatter plot of correlation between body mass index (BMI) and follicle-stimulating hormone (FSH) for women

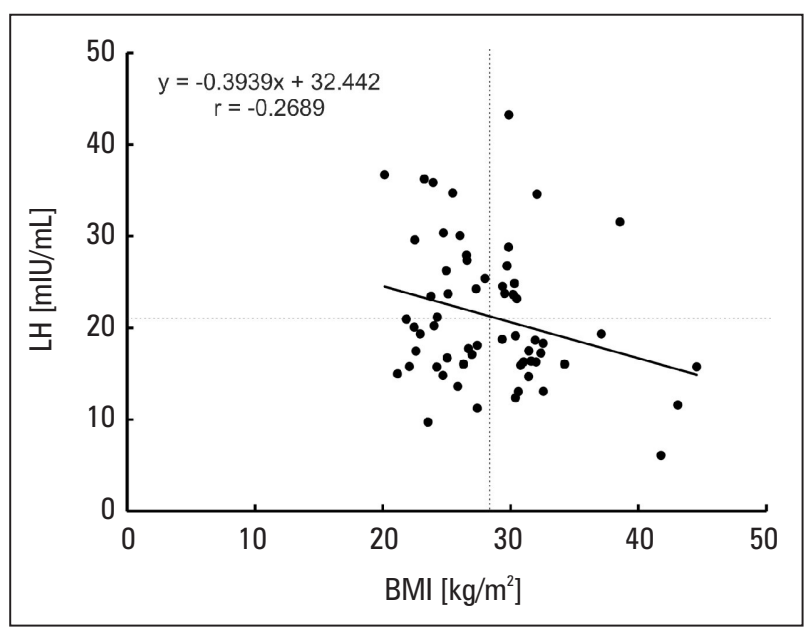

Figure 4. Scatter plot of correlation between body mass index (BMI) and luteinising hormone (LH) for women

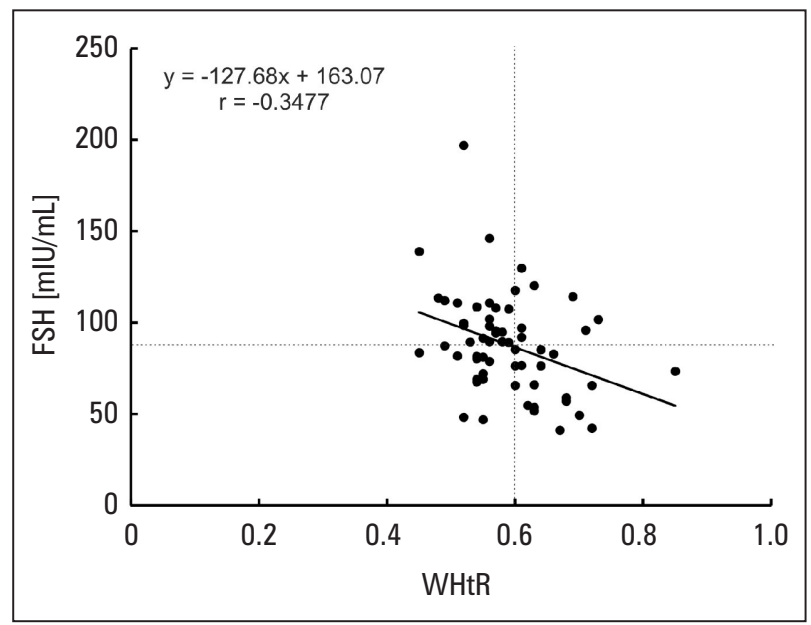

Figure 5. Scatter plot of correlation between waist-to-height ratio (WtHR) and follicle-stimulating hormone (FSH) for women

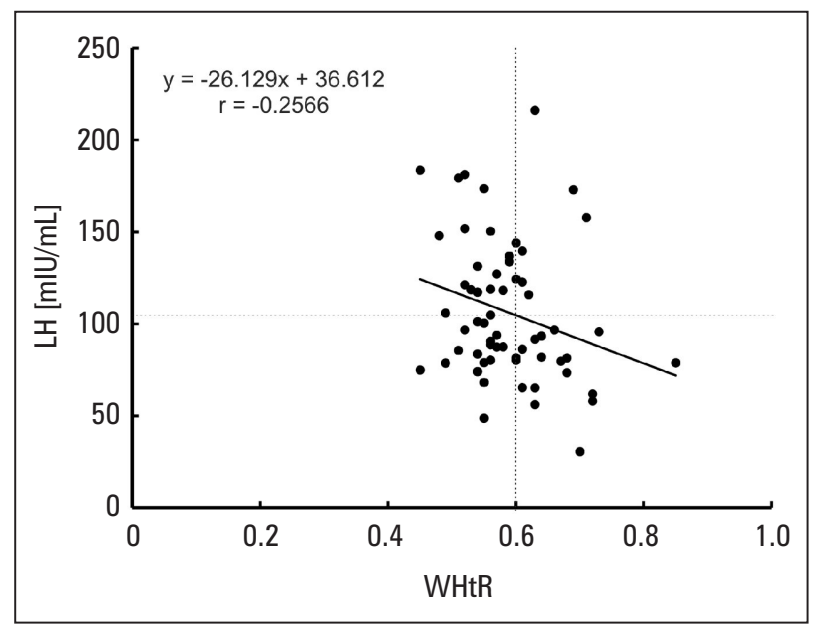

Figure 6. Scatter plot of correlation between waist-to-height ratio (WtHR) and luteinising hormone (LH) for women 
higher levels of DHEAs in men than in women are also concordant with earlier observations [3]. The higher levels of testosterone in men as compared to women are also obvious. Surprisingly, the mean concentration of E2 in men sharply exceeds the value observed in women. However, the same observation was done by Vermeulen et al. [24]. This finding can be explained by the higher availability of androgens (which are known to be the oestrogen precursors) in older men. The observed correlations between the particular examined hormones are rather expected. In spite of the occurrence of LH receptors in the human adrenal cortex (see Introduction), no correlation between LH and cortisol or DHEAs was found. Saxena and Seely [25] reported the positive correlation between LH and with urinary free cortisol in postmenopausal women, but (similarly to us) not with blood serum cortisol levels. The most interesting finding of our study is the demonstration of negative correlations between gonadotropin levels and body mass indices in women. Our results suggest a negative effect of elevated gonadotropins on the body mass, presumably on fat deposits and their distribution. Because mediation of the ovary is unlikely in older women, we conclude that gonadotropins may influence the body mass by their direct extra-gonadal action. The lack of similar correlation in men may result from the well-known occurrence of lower gonadotropin increment during aging in this gender, but it may also depend on the lower number of investigated patients in the male group. Theoretically, the effect of gonadotropin excess on body mass observed in women may concern all principal body compartments, i.e. fat tissue, bone, and muscular system. The knowledge on the direct effects of FSH and $\mathrm{LH}$ on the fat tissue is very limited. The direct effects of gonadotropins were shown in the brown fat tissue in rats [26] and mice [27]. Liu et al. [28] reported on the expression of FSH receptors in human fat tissue using both RT-PCR and immunohistochemistry. Recently we have also shown in our laboratory that human periadrenal and breast fat tissue exhibits strong positive immunoreaction with antibodies against FSH and LH receptors (unpublished results). The authors quoted above conclude that the activation of these receptors activates the lipid biosynthesis, and the FSH excess is an important causal factor of age-related obesity [28]. They also observed positive correlations of FSH and BMI in aging subjects. However, their investigated groups were much younger (women 51-55 years, men 61-65 years) in comparison to our patients. It cannot be excluded that in more advanced age the function of gonadotropin receptors is shifted towards lipolysis. However, the role of FSH and LH receptors in the fat tissue of older subjects needs further de- tailed studies. On the other hand, the body mass loss evoked by gonadotropins may partially result from osteoporosis accelerated by FSH (see Introduction). The participation of sarcopenia cannot be also excluded. To our knowledge there are no data on the effects of gonadotropins on the muscular system, although the FSH receptors were identified in the skeletal muscles [28]. Further studies concerning the effects of gonadotropins on body composition in larger groups of older people are urgently needed.

\section{Funding support}

The study was supported by Medical University of Lodz - grant No. 503/5-020-02/503-51-001 and 503/1-153-03/503-11-003-18.

\section{Conflicts of interest not declared.}

\section{References}

1. Warren MP, Ng EPS. Menopause . In: Karasek MP. ed. Aging and age-related diseases: The basics. Nova Biomedical, New York 2006: 5-29.

. Medras M, Karasek M. Andropause. In: Aging and age-related diseases: the basics. Nova Biomedical, New York 2006: 31-46.

3. Pawlikowski M, Karasek M. Dehydroepiandrosterone (DHEA) in aging. In: Karasek M. ed. Aging and age-related diseases: the basics. Nova Biomedical, New York 2006: 65-81.

4. Pawlikowski M. Is gonadotropin excess involved in the process of aging? A hypothesis. Folia Medica Lodzensia. 1994; 21: 137-145.

5. Pawlikowski M. The effect of gonadal and gonadotropic hormones on the prostatic ganglion and superior cervical ganglion in male white rats. Acta Med Pol. 1962; 3: 171-183, indexed in Pubmed: 14484663.

6. Roels $\mathrm{H}$. he effect of some pituitary hormones on volume and DNA content of cell nuclei of the adrenal cortex in hypophysectomized-castrated rats. Exp Cell Res. 1963; 31: 407-415, doi: 10.1016/0014-4827(63)90017-x indexed in Pubmed: 14065131.

7. Mikolajczyk H, Pawlikowski T. Histologic changes in the adrenal cortex of hypophysectomized-gonadectomized rats treated with gonadotrophins or adrenocorticotrophin. Endokrynol Pol. 1965; 16(4): 359-369, indexed in Pubmed: 4285954.

8. Komorowski J, Pawlikowski M, Stepień H. Pituitary glycoprotein hormones and interleukins secretion. In vitro and in vivo human study. Ann NY Acad Sci. 1995; 762: 429-431, doi: 10.1111/j.1749-6632.1995.tb32357.x, indexed in Pubmed: 7668548

9. Pabon JE, Li X, Lei ZM, et al. Novel presence of luteinizing hormone/chorionic gonadotropin receptors in human adrenal glands. J Clin Endocrinol Metab. 1996; 81(6): 2397-2400, doi: 10.1210/jcem.81.6.8964884, indexed in Pubmed: 8964884.

10. Lasley B, Conley A, Morrison J, et al. Identification of Immunoreactive Luteinizing Hormone Receptors in the Adrenal Cortex of the Female Rhesus Macaque. Reprod Sci. 2016; 23(4): 524-530, doi: 10.1177/1933719115607991, indexed in Pubmed: 26516122.

11. Korol P, Jaranowska M, Pawlikowski M. Immunohistochemical demonstration of LH/CG receptors in non-neoplastic human adrenal cortex and adrenocortical tumors. Folia Histochem Cytobiol. 2019; 57(1): 23-27, doi: 10.5603/FHC.a2019.0003, indexed in Pubmed: 30924919.

12. Lei ZM, Rao CV, Kornyei JL, et al. Novel expression of human chorionic gonadotropin/luteinizing hormone receptor gene in brain. Endocrinology. 1993; 132(5): 2262-2270, doi: 10.1210/endo.132.5.8477671, indexed in Pubmed: 8477671.

13. AL-Hader AA, Lei ZM, Rao CV. Neurons from fetal rat brains contain functional luteinizing hormone/chorionic gonadotropin receptors. Bio Reprod. 1997; 56(5): 1071-1076, doi: 10.1095/biolreprod56.5.1071, indexed in Pubmed: 9160703.

14. Apaja PM, Harju KT, Aatsinki JT, et al. Identification and structura characterization of the neuronal luteinizing hormone receptor associated with sensory systems. J Biol Chem. 2004; 279(3): 1899-1906, doi: 10.1074/jbc.M311395200, indexed in Pubmed: 14581462

15. Barron AM, Verdile G, Martins RN. The role of gonadotropins in Alzheimer's disease: potential neurodegenerative mechanisms. Endocrine. 2006; 29(2): 257-269, doi: 10.1385/ENDO:29:2:257, indexed in Pubmed: 16785601. 
16. Webber KM, Casadesus G, Bowen RL, et al. Evidence for the role of luteinizing hormone in Alzheimer disease. Endocr Metab Immune Disord Drug Targets. 2007; 7(4): 300-303, indexed in Pubmed: 18220951.

17. Casadesus G, Rolston RK, Webber KM, et al. Menopause, estrogen, and gonadotropins in Alzheimer's disease. Adv Clin Chem. 2008; 45: 139-153, indexed in Pubmed: 18429496.

18. Bhatta S, Blair JA, Casadesus G. Luteinizing Hormone Involvement in Aging Female Cognition: Not All Is Estrogen Loss. Front Endocrinol (Lausanne). 2018; 9: 544, doi: 10.3389/fendo.2018.00544, indexed in Pubmed: 30319538

19. Robinson LJ, Tourkova I, Wang Y, et al. FSH-receptor isoforms and FSH-dependent gene transcription in human monocytes and osteoclasts. Biochem Biophys Res Commun. 2010; 394(1): 12-17, doi: 10.1016/j. bbrc.2010.02.112, indexed in Pubmed: 20171950.

20. Wang J, Zhang W, Yu C, et al. Follicle-Stimulating Hormone Increases the Risk of Postmenopausal Osteoporosis by Stimulating Osteoclast Differentiation. PLoS One. 2015; 10(8): e0134986, doi: 10.1371/journal. pone.0134986, indexed in Pubmed: 26241313.

21. Sun Li, Peng Y, Sharrow AC, et al. FSH directly regulates bone mass. Cell. 2006; 125(2): 247-260, doi: 10.1016/j.cell.2006.01.051, indexed in Pubmed: 16630814.
22. Chin KY. The Relationship between Follicle-stimulating Hormone and Bone Health: Alternative Explanation for Bone Loss beyond Oestrogen? Int J Med Sci. 2018; 15(12): 1373-1383, doi: 10.7150/ijms.26571, indexed in Pubmed: 30275766.

23. Pawlikowski M. Direct actions of gonadotropins beyond the reproductive system and their role in human aging and neoplasia. Endokrynol Pol. 2019; 70(5): 437-444, doi: 10.5603/EP.a2019.0034, indexed in Pubmed: 31681968

24. Vermeulen A, Kaufman JM, Goemaere S, et al. Estradiol in elderly men. Aging Male. 2002; 5(2): 98-102, indexed in Pubmed: 12198740.

25. Saxena AR, Seely EW. Luteinizing hormone correlates with adrenal function in postmenopausal women. Menopause. 2012; 19(11): 1280-1283, doi: 10.1097/gme.0b013e31825540c4, indexed in Pubmed: 22713862.

26. Romer TE. Effect of FSH and chorionic gonadotropins on the morphological pattern of brown fat tissue in rats. (in Polish). Endokrynol Pol. 1964; 15: 643-649, indexed in Pubmed: 14329366.

27. Liu P, Ji Y, Yuen T, et al. Blocking FSH induces thermogenic adipose tissue and reduces body fat. Nature. 2017; 546(7656): 107-112, doi: 10.1038/nature22342, indexed in Pubmed: 28538730.

28. Liu XM, Chan HC, Ding GL, et al. FSH regulates fat accumulation and redistribution in aging through the $\mathrm{G} \alpha \mathrm{i} / \mathrm{Ca}(2+) / \mathrm{CREB}$ pathway. Aging Cell. 2015; 14(3): 409-420, doi: 10.1111/acel.12331, indexed in Pubmed: 25754247. 